\title{
Graphic Life Writing in Kaisa Leka's I Am Not These Feet
}

\section{Leena Romu}

\begin{abstract}
Numerous graphic novels published in recent years are autobiographical. The autobiographical trend is noticeable in the Finnish comics scene with cartoonists drawing inspiration from real life. Kaisa Leka is a noteworthy Finnish autobiographical comic book artist who has published comics based on her life experiences. Leka's stories focus on the construction of her identity: who she is as a person, as a comic book artist and as a practitioner of Hare Krishna ${ }^{1}$. Both her feet were amputated due to a congenital malformation. Her comic book I Am Not These Feet (2003) concentrates on the process of the amputation. The chapter discusses the representations of embodiment in I Am Not These Feet by applying the concept of pictorial embodiment refined in the works of comics scholar Elisabeth El Refaie. The emphasis is on the drawing style and pictorial choices used in depicting bodies, disability and gender.
\end{abstract}

Key Words: Disability, performativity, autobiographical comics, pictorial embodiment, gender, Kaisa Leka.

$* * * * *$

\section{Disabled Mickey Mouse?}

I Am Not These Feet is Kaisa Leka's most well-known comic book and notwithstanding more than a decade of its publication, it still defines her artistic career. ${ }^{2}$ Although Leka does not depict disability in her more recent books in an explicit way, she is still referred to as a disabled artist. ${ }^{3}$ In her comic books, Leka uses naïve and simple line drawings that do not reveal any details of the characters or story world. People are depicted as simplified animal caricatures, usually as mice that draw inspiration from the world famous characters of Walt Disney. According to Leka, with I Am Not These Feet she sought to break the silence and shame that surround disability and sickness. ${ }^{4}$ A protagonist that bears a resemblance to Mickey Mouse invites people to read her story and reaches readers who otherwise would not pick up a book about disability. The artist admits that first the mouse character was also a parody of Mickey Mouse because, for her, Mickey represents culturally hegemonic normality. ${ }^{5}$ In Leka's books, the always cheerful and energetic Disney character is transformed in order to depict a vulnerable and fallible human being.

Because Leka talks openly about her disability in interviews, people are eager to see her prostheses. In I Am Not These Feet the reader's curiosity gets fulfilled already on the cover where six photographs of the author and her prosthetic feet are arranged in a grid-like layout (see Image 1). The photographs form a sequence and 
the reader is encouraged to construct a narrative by interpreting the order and framing of the images and the bodily postures and gestures of the portrayed artist. By using photographs instead of drawn pictures the cover makes claims about the historical accuracy and authenticity of the depicted events to such a degree that no label of 'Based on a true story' is required. The reader may feel sympathy or pity for the artist because of her disability but the colourful cover attempts to affirm that the story will be a happy one. The artist smiles to the reader and seems to have an active life: she swings happily and rides a scooter with her boyfriend. In this regard, the cover also raises expectations about the narrative as a survival story.

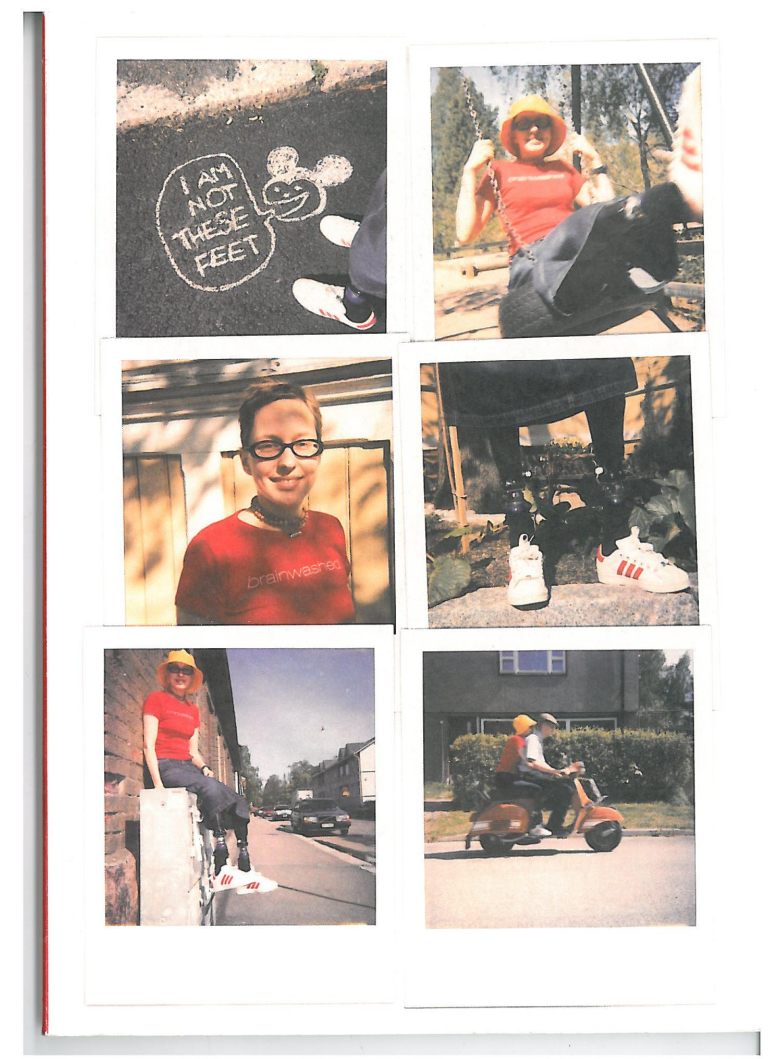

Image 1: The cover of I Am Not These Feet. Used with permission.

\section{Distancing the Reader}


The body can be regarded as one of the key themes in many autobiographical comics or graphic memoirs. The autobiographical comics genre offers artists several possibilities to represent their physical identities and, according to comics scholar Elisabeth El Refaie, this process of engaging with one's own identity through self-portraits can be referred to as pictorial embodiment. ${ }^{6}$ An autobiographical comics artist is forced to visually portray herself panel after panel which necessarily involves some engagement with the body and body image. ${ }^{7}$ The artist must decide and choose what features she wants to render and how she wants herself to be seen by the reader. From this aspect, the representations of self can be seen as products of performative and repetitive act.

According to Judith Butler, people construct their gender and identity through imitative and rehearsed practices. In fact, the body is shaped by political forces and must not be considered as a passive medium but as a site of negotiation. Political regulations and disciplinary practices affect how bodies and gender are understood and constructed. ${ }^{8}$ The whole strategy of constructing one's body image is a continuous act that is both intentional and performative but always also dependent on cultural and political regulations. In other words, there is no such thing as a 'natural body' since all bodies are defined and redefined in cultural discourses. ${ }^{9}$ I use the concept of performativity in my reading of Leka's book as an interpretational strategy for scrutinising how Leka depicts herself and what political or ideological aspirations may be behind her formal and stylistic choices.

Leka does not provide any details of her malformed original feet on the cover and in the story she draws her legs after the amputation by using only a couple of black lines. This can frustrate the reader's desire to see the author's deformity and the simplified style allows the author to control the distance between the author and reader. ${ }^{10}$ In this respect, the author can also control how her body is seen by others in a way that is not possible in the real life. Instead of getting detailed information about the original malformed feet, the reader obtains elaborate facts about the new prosthetic feet in a couple of large pictures. The reader acquires details about the material of the prostheses (carbon fibre) and how they can be adjusted to make the protagonist a bit taller than before the operation.

However, overall in the story, her prostheses seem to be nothing else but a couple of black lines with white loops at the base. Interestingly, on the penultimate page, the prostheses become visually part of the protagonist and they are drawn in the same style as the feet of the other characters. The omission to depict this physical difference continues in Leka's more recent books where she tells, for example, about her bicycle trip across Europe. According to El Refaie, people with a serious illness or disability are often judged by their different appearance and they are perceived as more 'fully body' than others. ${ }^{11}$ By drawing herself in the same style as she draws the other characters, Leka refuses to be defined only by her disability. In other words, on the pages of the comic book she can decide how she wants to perform her body in relation to the idea of a normative healthy body. 


\section{Drawing the Difference}

Butler's idea of performativity has been used widely in discussions about the construction of gender. According to Butler, gender identity is constructed by imitating cultural understandings of gender and in Western culture gender has traditionally been divided into feminine and masculine. ${ }^{12}$ Leka draws people in her book as identical mice that are distinguishable only by initialled t-shirts or slightly different clothing. The sole exception is her boyfriend who is depicted as a duck and hence his role in the life of the protagonist is underlined. The reader does not get any visual clues about the gender of the characters which can be interpreted as the artist's commentary on the conventions of depicting gender in popular culture. In this comic book we do not see exaggerated eyelashes or other minor physical features that are often used, for example, in funny animal comics so as to help the reader to identify the characters as female. ${ }^{13}$

El Refaie claims that 'Every time autobiographical comics artists draw themselves and those around them, they cannot avoid engaging with the sociocultural models that underpin body image, including categories of sex, gender, health, and beauty. ${ }^{14}$ However, instead of highlighting physical, cultural, social or gender differences Leka chooses to emphasise the shared human experience. Her anthropomorphic animal characters do not promote a certain body image but provide equal freedom for everyone to determine how their own bodies are defined. El Refaie continues that pictorial embodiment is always profoundly social and political activity and in the light of this remark Leka's simplified caricatures appear to be more than silly animal characters. ${ }^{15}$

The refusal to categorise people is also depicted in terms of the content of $\mathrm{IAm}$ Not These Feet. In the next example (see Image 2), the main character is situated in the bottom right corner of the page-sized panels and above her hovers a huge speech bubble full of text. 

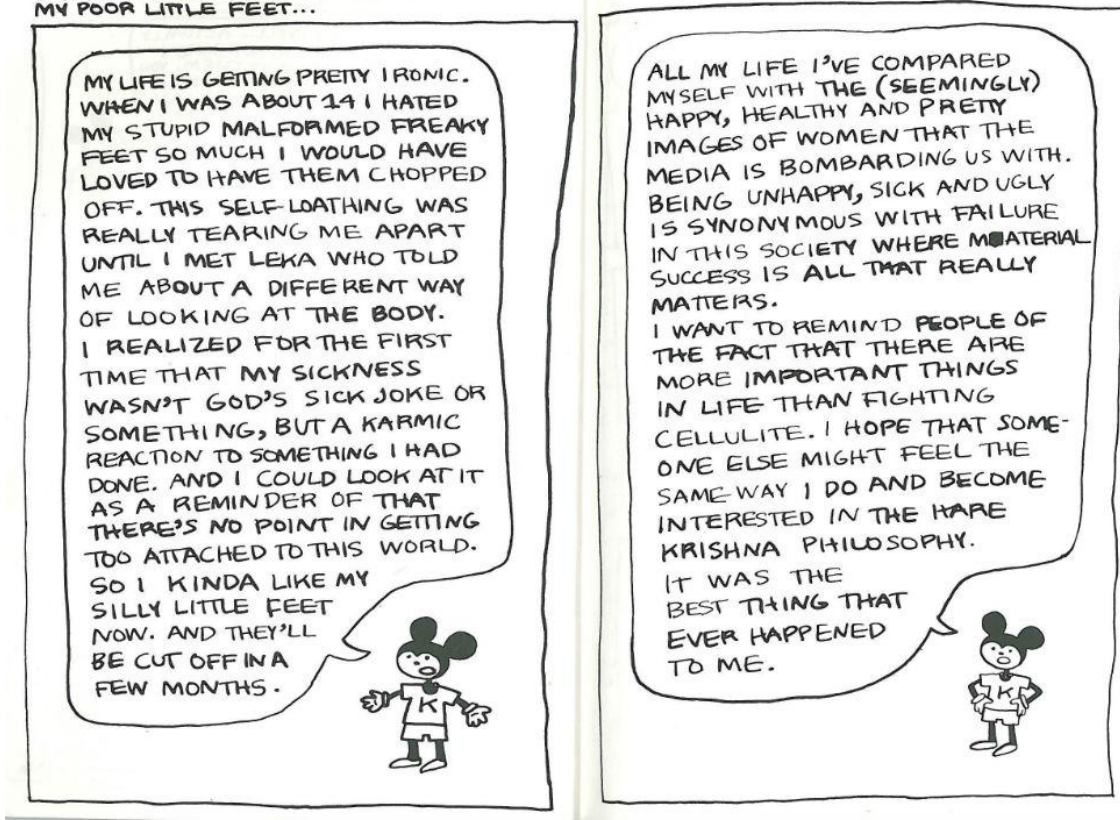

Image 2: I Am Not These Feet. Used with permission.

In the speech bubble, the protagonist relates her inner turmoil and low self-esteem caused by the contradiction between her malformed figure and the imagery of a perfect woman presented in media. By using an ironic tone she seeks to remind people of 'the fact that there are more important things in life than fighting cellulite'. Her speech adopts a religious tone when she pronounces that her life changed when she became interested in the Hare Krishna movement and realised that it is up to her how she wishes to perceive herself and to be perceived by others. The critique attacks the Western consumer culture and culturally accepted beauty norms that force individuals to constantly monitor their own and other people's bodies. As such, Leka underlines the performative aspect of gender and identity and questions the dominant ways of performing oneself. The choice of drawing herself as a simplified mouse caricature that does not physically differ from the other characters can be seen as a formal strategy that realises her body politics and the criticism towards material thinking. Thus, the style of drawing can be considered as a narrative strategy that persuades the reader to accept the author's ideological views. 


\section{Breaking up the Visual Surface}

While El Refaie is interested in the pictorial representations of the body she leaves aside the relevance of textual elements. If we consider the pictorial embodiment as a performative act, we have to scrutinise the handwriting as a part of it. Like Leka's drawing style, the handwritten lettering is undecorated consisting of even and plain upper case letters. Interestingly, occasional misspellings and errors in the text have been corrected in a manner that leaves the blotches of ink visible. For example, on the aforementioned spread (see Image 2) the word material is accentuated because of a misspelling. It can be claimed that the errors are incidental but further contemplation might be prolific. Comics scholar Hillary Chute analyses the visually versatile and constantly transforming lettering of comics artist Lynda Barry and contends that the shifting of the lettering style, size and colouring even in the middle of a word is enacted to break up the actual visual surface of the text. ${ }^{16}$ Similarly, it can be affirmed that in Leka's comics the misspellings in the lettering breach the uniformity of the text and, moreover, call attention to the craftedness of the work. Further, the errors can be interpreted as underlining the documental value of the comic book: the distance between the author and reader diminishes when the author reveals her liability to error. If we connect the flaws in the textual elements to the performative project of constructing the self, we can also claim that by leaving the errors visible Leka once again underlines her body politics. Thus, the title I Am Not These Feet can be changed into 'I am not these flaws'.

On the title page, the narrative is labelled as a diary ('Kaisa's diary 5') and the choice of the diary genre can be observed as an attempt to highlight the authenticity of the depicted events. Diary has been considered an acceptable form for delving personal and intimate issues and at the same time it is regarded as a feminine form of writing. Comics scholar Bart Beaty notes that diary has often been characterised as 'existing outside the mainstream of heroic and masculine autobiography'. ${ }^{17}$ However, the rhetoric effects of diaristic writing conflict with Leka's drawing style that does not support the intimacy of the form. In my view, the choice of a genre that is normally used for depicting mental activity collides with the distancing drawing style that omits the portrayal of emotions.

In I Am Not These Feet, the depressive and sad moments of the main character are conveyed mainly via verbal means because the pictorial cues, for example postures and facial expressions, are minimal. In the final example from the book (see Image 3), we see twelve panels which depict the main character in almost unchangeable positions. She sits in a wheelchair and looks straight at the reader. The author maintains the distance to the reader by controlling the depiction of her emotional reactions. The expression on Kaisa's face remains almost immutable and variations in the depiction of the forehead, eyes and hand are almost unnoticeable. 
TUESDAY MARCH 19TH-WEDNESDAY MARCH $201 \mathrm{H}, 2002$

I'M THINKING OF MY WOUNDS
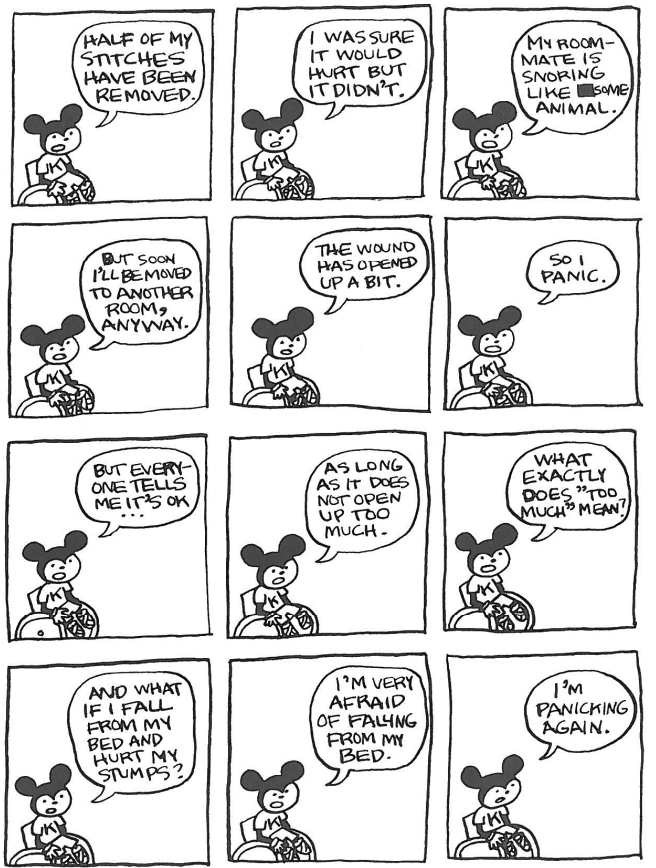

Image 3: I Am Not These Feet. Used with permission.

\section{Conclusions}

Autobiographical comics are considered as a means to perform and actively recreate one's identity. The presence of the body and focus on embodiment in autobiographical comics encourage the use of the concept of performativity. In addition, the fact that autobiographical writing has been considered as a performative act requires pondering what those visual means in comics storytelling are that engage in the construction of the self. If we claim that bodies are performative, we claim that bodies are never merely described but always constituted in the act of description. ${ }^{18}$

In this chapter, I have analysed Kaisa Leka's comic book by using the concept of pictorial embodiment. I have shown how the simplistic drawing style and handwritten lettering work as a part in Leka's body politics but also as ways to 
negotiate the distance between the reader and author. I have suggested a reading that considers both the content and form as inseparable parts of the project of performing self but also as means to convey the artist's political and philosophical views. It is important to note that discussing the performativity of autobiographical comics does not imply that constructing self could be seen as merely straightforward theatre. When discussing I Am Not These Feet, we can say that the artist chooses the means to perform her identity, gender and body and in this way the choices can be seen as extensions of her own body project. Nevertheless, we should be wary and not claim that by reading I Am Not These Feet we can unravel the body image of the real author. Rather, the idea of performativity can assist as a concept to understand the representations of embodiment and the stylistic choices in Leka's comic book.

\section{Notes}

${ }^{1}$ Leka openly tells about her relation to Hare Krishna philosophy, a theme that is essential also in her other comic books (See e.g. On the Outside Looking in, 2006, and Tour d'Europe, 2011).

${ }^{2}$ In a radio interview, Leka explains how she still often gets questions concerning $I$ Am Not These Feet although she has published several comic books since the title (See Lindeberg, Aura and Jukka Lindström. Interview with Kaisa Leka. YleX Etusivu. YleX, January 25, 2012).

${ }^{3}$ See for example, Sandahl Carrie: 'Kaisa Leka: Confusing the Disability/Ability Divide' in Art and Social Justice Education. Culture as Commons, ed. Therese Quinn and John Ploof and Lisa Hochtritt (New York and London: Routledge, 2012).

${ }^{4}$ Antonio Díaz: 'When Disability Turns into Virtuosity - Interview With Kaisa Leka' in Free! Magazine, November 9, 2007.

${ }^{5}$ See Leka's interview in Nono blog, January 5, 2007. Viewed 15 October 2013. http://nono102.blogspot.fi/2007/01/haastattelu-kaisa-leka.html.

${ }^{6}$ Elisabeth El Refaie: Autobiographical Comics. Life Writing in Pictures (Jackson: University Press of Mississippi 2012), 51.

${ }^{7}$ Ibid.

${ }^{8}$ Judith Butler: Gender Trouble. Feminism and the Subversion of Identity (New

York \& London: Routledge 1999), 164.

${ }^{9}$ Sara Salih: 'On Judith Butler and Performativity' in Sexualities and

Communication in Everyday Life. A Reader, ed. Karen E. Lovaas and Mercilee M. Jenkins (London: SAGE Publications Ltd), 55.

${ }^{10}$ See also Ian Williams: 'Graphic Medicine: How Comics Are Revolutionizing the Representation of Illness' in Hektoen International. A Journal of Medical Humanities. 
${ }^{11}$ El Refaie, Autobiographical Comics, 73.

${ }^{12}$ Butler, Gender Trouble, 30-31.

${ }^{13}$ Trina Robbins 'Gender Differences in Comics'. In Image [\&] Narrative, Vol.II: 2 (4), 2002. Viewed 15 October 2013.

http://www.imageandnarrative.be/inarchive/gender/trinarobbins.htm.

${ }^{14}$ El Refaie, Autobiographical Comics, 73.

${ }^{15}$ Ibid.

${ }^{16}$ Hillary Chute: Graphic Women. Life Narrative and Contemporary Comics (New York: Columbia University Press, 2010), 110-111.

${ }^{17}$ Bart Beaty: Unpopular Culture. Transforming the European Comic Book in the 1990s (Toronto: University of Toronto Press, 2007), 162.

${ }^{18}$ Salih, 'On Judith Butler and Performativity', 61.

\section{Bibliography}

Beaty, Bart. Unpopular Culture. Transforming the European Comic Book in the 1990s. Toronto: University of Toronto Press, 2007.

Butler, Judith. Gender Trouble. Feminism and the Subversion of Identity. New York \& London: Routledge, 1999.

Chute, Hillary. Graphic Women. Life Narrative and Contemporary Comics. New York: Columbia University Press, 2010.

Díaz, Antonio. 'When Disability Turns into Virtuosity - Interview With Kaisa Leka' in Free! Magazine, November 9, 2007. Viewed 15 October 2013. http://www.freemagazine.fi/when-disability-turns-into-virtuosity/.

El Refaie, Elisabeth. Autobiographical Comics: Life Writing in Pictures. Jackson: University Press of Mississippi, 2012.

Leka, Kaisa. Tour d'Europe. Helsinki: Absolute Truth Press, 2010.

—. On the Outside Looking In. Helsinki: Absolute Truth Press, 2006.

—. I Am Not These Feet. Helsinki: Absolute Truth Press, 2003.

Lindeberg, Aura and Jukka Lindström. 'Interview with Kaisa Leka.' YleX Etusivu. YleX, January 25, 2012. Listened 15 October 2013. 
http://ylex.yle.fi/radio/vieraat/ylex-etusivun-vieraana-sarjakuvataiteilija-kaisa-lekadisney-maailmassa-ei-ole-politii

Robbins, Trina. 'Gender Differences in Comics'. In Image [\&] Narrative, Vol.II: 2 (4), 2002. Viewed 15 October 2013.

http://www.imageandnarrative.be/inarchive/gender/trinarobbins.htm.

Salih, Sara. 'On Judith Butler and Performativity'. In Sexualities and Communication in Everyday Life. A Reader. Edited by Karen E. Lovaas and Mercilee M. Jenkins. London: SAGE Publications, Ltd, 2007, 55-67.

Sandahl, Carrie. 'Kaisa Leka: Confusing the Disability/Ability Divide'. In Art and Social Justice Education: Culture as Commons. Edited by Therese Quinn, John Ploof and Lisa Hochtritt. New York: Routledge, 2012, 53-55.

Williams, Ian. 'Graphic medicine: how comics are revolutionizing the representation of illness'. Hektoen International. A Journal of Medical Humanities, 2010. Viewed 15 October 2013.

http://www.hektoeninternational.org/graphicMedicine.html.

Leena Romu is a postgraduate student in the School of Language, Translation and Literary Studies at the University of Tampere, Finland. She is currently writing her doctoral thesis on the representations of embodiment in Finnish comics. 